\title{
Relationship between body posture and dento-facial deformities
}

\author{
M. Milkov, M. Stoykov \\ Faculty of Dental medicine, Medical University - Varna
}

\begin{abstract}
:
The aim of this study is to investigate the possible relationship between dento-facial deformities, craniofacial morphology and body posture anomalies. It is recommended that specialists in orthodontics give attention to the cervical vertebral column area on profile radiographs to include any deviations in the cervical vertebral column morphology and head posture, while considering diagnosis and evaluation of etiology in orthodontic patients with skeletal craniofacial deviations and in patients with obstructive sleep apnea (OSA).
\end{abstract}

Key words: dento-facial deformities, craniofacial morphology, malformation, posture

\section{Introduction}

It is recommended that specialists in orthodontics give attention to the cervical vertebral column area on profile radiographs to include any deviations in the cervical vertebral column morphology and head posture, while considering diagnosis and evaluation of etiology in orthodontic patients with skeletal craniofacial deviations and in patients with obstructive sleep apnea (OSA).

Craniofacial morphology described on profile radiographs is an important diagnostic tool in orthodontic treatment planning. Björk's analyses were some of the earliest cephalometric analyses that described the vertical and horizontal relationships of the jaws with the cranial base as well as the interrelationship between the jaws. Furthermore, the relation between jaws, teeth, and alveolar bone was described. In 1955, Björk (3) conducted the first human growth study using implants, which resulted in the discovery of the rotation of the jaws. In the following years, cephalometric analyses were further developed to include analyses of growth and treatment changes and, to some extent, prediction of the growth. (4)

Later, cephalometric analyses were performed on the cervical vertebral column area. It was found that the dimensions of the first cervical vertebra (C1), the atlas, and the posture of the head and neck were associated with factors such as craniofacial morphology, including the cranial base, $(7,9$, $19,20)$ upper airway space, $(15,17)$ and, to some extent, occlusion $(7,8,18)$ and temporomandib- 
ular disorders. $(11,20,32)$ Many cross-sectional studies agree on the relationship between extended head posture and craniofacial structures. $(7,9,20)$ In subjects with extended head posture, increased anterior facial height, reduced sagittal jaw dimensions, and a steeper inclination of the mandible were generally observed. When the head was bent in relation to the cervical column, a shorter anterior facial height, larger sagittal jaw dimensions, and a less steep inclination of the mandible were observed.

Some longitudinal studies (16) likewise demonstrated that growth changes in head posture were related to corresponding changes in the growth pattern of the facial skeleton. When the head was extended, a reduced forward rotation of the mandible was observed. Some studies have also shown that the transverse dimensions of the maxilla and the maxillary dental arch width were associated with the posture of the head and neck. An increased occurrence of posterior crossbite and a smaller width of the maxilla were observed in subjects with an extended head posture. $(1,10,12)$

Many cephalometric studies have been performed on patients with OSA, and most authors agree that craniofacial morphological and postural characteristics exist in patients with OSA, such as reduced posterior airway space, abnormally long soft palate, low position of the hyoid

bone, and an extended head posture. $(5,33)$

Aim: The aim of this study is to investigate the possible relationship between dento-facial deformities, craniofacial morphology and body posture anomalies.

\section{Material and methods}

The following scientific research databases were included in the study: MEDLINE, Scopus, EMBASE and PubMed, with a time period between 1955 and 2020. For search the keywords dento-facial deformities, craniofacial morphology, malformation, posture and balance were used.

\section{Results and discussion}

Anomalies of the cervical vertebral column morphology of the upper 5 cervical vertebrae (C1-C5) on a lateral skull radiograph are usually divided into 2 main categories: fusion anomalies and posterior arch deficiency. (14)

Fusion anomalies are fusion, block fusion, and occipitalization. (29) Fusion is defined as fusion 52 of one unit with another at the articulation facets, neural arch, or transverse processes. Occipitalization is the term for assimilation, either partially or completely, of the atlas (C1) with the occipital bone. The definition of block fusion was modified according to Sonnesen and Kjær (21) - a fusion of more than 2 units at the vertebral bodies, articulation facets, neural arch, or transverse processes. Posterior arch deficiency consists of partial cleft and dehiscence. (14) Partial cleft is a failure of the posterior part of the neural arch to fuse. Dehiscence is defined as failure to develop part of a vertebral unit.

Deviations of the cervical column morphology occur in healthy subjects with neutral occlusion and normal craniofacial morphology as well as in patients with craniofacial syndromes, deviating craniofacial morphology, and severe malocclusion traits.

A recent study found that fusions between the upper cervical vertebrae (C2 and $\mathrm{C} 3$ ) occurred in $14.3 \%$ of healthy subjects. (21) Fusions of the upper cervical column within that range are thus considered normal.

Previous studies have established an association between malformations of the upper cervical vertebrae and patients with cleft lip and palate. $(6,31)$ Recently, an association was also found between malformation of the upper cervical vertebrae not only in patients with condylar hypoplasia, (21) but also in adult orthodontic surgical patients with skeletal deep bite, (23) skeletal mandibular overjet, (24) skeletal horizontal overjet, and skeletal open bite. These studies showed that cervical column deviations occurred in $72.7 \%$ of the condylar hypoplasia group, $41.5 \%$ of the deep-bite group, $61.4 \%$ of the mandibular-overjet group, $52.9 \%$ of the horizontal-overjet group, and $42.1 \%$ of the open-bite group. Deviations occurred significantly more often in all 5 patient groups compared with the control group. This indicates that morphologic deviations of the upper cervical vertebrae are not only associated with malformation of the jaws but also with craniofacial morphology and occlusion. A study of adults found that fusion between $\mathrm{C} 2$ and C3 was significantly associated with posture of the head and neck. (21) In this study, the cervical vertebral column was approximately $5^{\circ}$ more curved, and the inclination of the upper cervical spine was $8^{\circ}$ more backward in adults with fusion.

Accordingly, associations have been reported 
between craniofacial morphology and head posture, between OSA, craniofacial morphology, and head posture (Fig. 1), and between morphological deviations of the cervical vertebral column and craniofacial syndromes $(2,6,13,30,31)$ and cleft lip and/or palate.

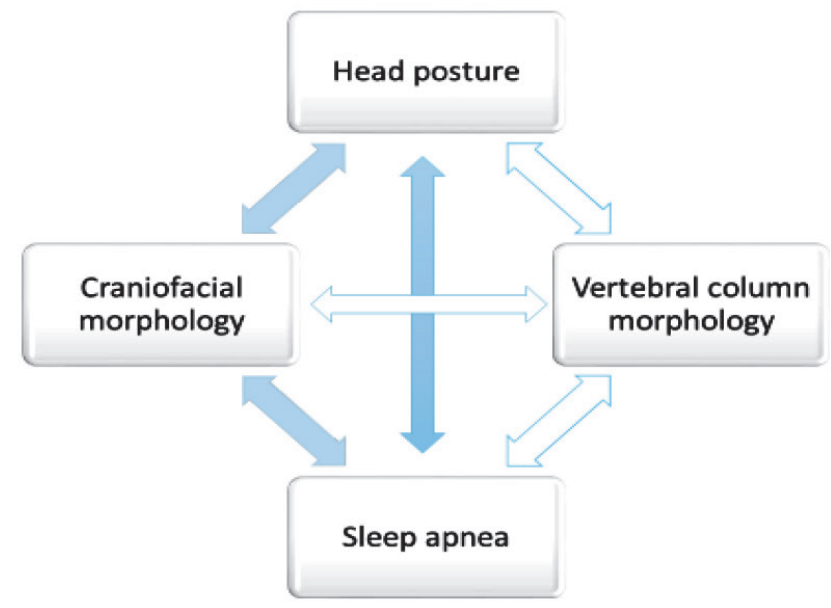

Figure 1. Schematic illustration of associations between craniofacial morphology, head posture, cervical vertebral column morphology, and sleep apnea.

A series of studies were performed on associations between morphological deviations of the cervical vertebral column and the craniofacial morphology in adult patients with severe skeletal malocclusion traits. $(21,23,26,27)$ In these studies, it was revealed that fusion of the cervical vertebral column was associated with craniofacial morphology. A significant association between fusion and a large craniofacial base angle, between fusion and retrognathia of the jaws, and between fusion and inclination of the jaws was found in patients with severe skeletal malocclusions, indicating an association between fusion of the cervical vertebral column and craniofacial morphology, including a large cranial base angle.

Recently, morphological deviations of the cervical vertebral column have been described in healthy subjects with neutral occlusion and normal craniofacial morphology $(21,25)$ and in patients with severe skeletal malocclusion traits, such as skeletal deep bite, skeletal open bite, skeletal maxillary overjet, and skeletal mandibular overjet. $(21,23$, 26, 27)

A study on cervical vertebral column morphology in patients with OSA found that the prevalence of fusion anomalies of the cervical vertebral col- umn was 46\%. (28) In addition, the prevalence of fusion anomalies of the cervical vertebral column occurred significantly more often and at a lower level in the column in patients with OSA compared with subjects with neutral occlusion and normal craniofacial morphology. (28) Fusion anomalies occurred in the OSA patients as fusions between the second and third vertebrae, the third and fourth vertebrae, or between the fourth and fifth vertebrae. Block fusions occurred in the OSA patients in combination with fusions and block fusions. (28)

An association between posture of the head and neck and the cervical vertebral column morphology has been found in a recent study on subjects with neutral occlusion and normal craniofacial morphology. (22) The study showed that the cervical lordosis was significantly more curved in subjects with fusion than in subjects without fusion. Furthermore, the inclination of the upper cervical column was more backward in subjects with fusion than in subjects without fusion. (22) The findings of this recent study indicate an association between fusion of the cervical column and the posture of the neck. (22)

The findings described earlier indicate that fusion of the cervical vertebral column is associated with occlusion, craniofacial morphology, and head posture in nonsyndromic patients.

\section{Conclusion}

It is suggested that head posture has an impact on the development and function of the craniofacial morphology, and that the morphological patterns of the upper cervical vertebrae could play a role in the etiology of patients with OSA. Deviations of cervical vertebral column morphology were significantly associated with a large sagittal jaw relationship, retrognathia of the jaws, a large inclination of the jaws, and a large cranial base angle. Furthermore, deviations in the cervical vertebral column morphology were significantly associated with extension of the head in relation to the cervical vertebral column. The associations between cervical column morphology, craniofacial morphology, and head posture have not previously been described in preorthodontic children with horizontal maxillary overjet. These new findings are considered to be important for the diagnosis and more accurate treatment of children with horizontal maxillary overjet. 


\section{References}

1. AlKofide EA, AlNamankani E: The association between posture of the head and malocclusion in Saudi subjects. Cranio 25:98-105, 2007

2. Anderson PJ, Hall CM, Evans RD, et al: Cervical spine in Pfeiffer's syndrome. J Craniofac Surg 7:275-279, 1996

3. Björk A: Facial growth in man, studied with the aid of metallic implants. Acta Odontol Scand 13:9-34, 1955

4. Björk A, Skieller V: Normal and abnormal growth of the mandible. A synthesis of longitudinal cephalometric implant studies over a period of 25 years. Eur J Orthod 5:1-46, 1983

5. Hoekema A, Hovinga B, Stegenga B, et al: Craniofacial morphology and obstructive sleep apnoea: A cephalometric analysis. J Oral Rehabil 30:690-696, 2003

6. Horswell BB. The incidence and relationship of cervical spine anomalies in patients with cleft lip and/or palate. J Oral Maxillofac Surg 1991; 49:693-7

7. Huggare J: Association between morphology of the first cervical vertebra, head posture, and craniofacial structures. Eur J Orthod 13:435440, 1991

8. Huggare J, Harkness E: Associations between head posture and dental occlusion. J Dent Res 72:255, 1993

9. Huggare J, Houghton P: Associations between atlantoaxial and craniomandibular anatomy. Growth Dev Aging 60:21-30, 1996

10. Huggare J: Postural disorders and dentofacial morphology. Acta Odontol Scand 56:383-386, 1998

11. Lee WY, Okeson JP, Lindroth J: The relationship between forward head posture and temporomandibular disorders. J Orofac Pain 9:161-167, 1995

12. McGuinness NJ, McDonald JP: Changes in natural head position observed immediately and one year after rapid maxillary expansion. Eur J Orthod 28:126-134, 2006

13. Rajion ZA, Townsend GC, Netherway DJ, et al: A threedimensional computed tomographic analysis of the cervical spine in unoperated infants with cleft lip and palate. Cleft Palate Craniofac J 43:513-518, 2006

14. Sandham A: Cervical vertebral anomalies in cleft lip and palate. Cleft Palate J 23:206-214, 1986

15. Solow B, Siersbaek-Nielsen S, Greve E: Airway adequacy, head posture, and craniofacial morphology. Am J Orthod 86:214-223, 1984

16. Solow B, Siersbaek-Nielsen S: Cervical and craniocervical posture as predictors of craniofacial growth. Am J Orthod Dentofacial Orthop 101:449-458, 1992

17. Solow B, Skov S, Ovesen J, et al: Airway dimensions and head posture in obstructive sleep apnoea. Eur J Orthod 18:571-579, 1996

18. Solow B, Sonnesen L: Head posture and malocclusions. Eur J Orthod 20:685-693, 1998

19. Solow B, Sandham A: Cranio-cervical posture: A factor in the development and function of the dentofacial structures. Eur J Orthod 14:447456,2002

20. Sonnesen L, Bakke M, Solow B: Temporomandibular disorders in relation to craniofacial dimensions, head posture and bite force in children selected for orthodontic treatment. Eur J Orthod 23:179-192, 2001

21. Sonnesen L, Kjær I: Cervical column morphology in patients with skeletal Class III malocclusion and mandibular overjet. Am J Orthod Dentofacial Orthop 132: e7-12, 2007

22. Sonnesen L, Pedersen C, Kjær I. Cervical column morphology related to head posture, cranial base angle and condylar malformation. Eur J Orthod 2007; 29:1-6

23. Sonnesen L, Kjær I. Cervical vertebral body fusions in patients with skeletal deep bite. Eur J Orthod 2007; 29:464-70

24. Sonnesen L, Kjær I. Cervical column morphology in patients with skeletal Class III malocclusion and mandibular overjet. Am J Orthod Dentofacial Orthop 2007; 132: 427:e1-7

25. Sonnesen L, Pallisgaard C, Kjær I: Cervical column morphology and craniofacial profiles in monozygotic twins. Twin Res Hun Genet 11:8492,2008

26. Sonnesen L, Kjær I: Anomalies of the cervical vertebrae in patients with skeletal Class II malocclusions and horizontal maxillary overjet. Am J Orthod Dentofacial Orthop 2008; 133: 188.e15-188.e20

27. Sonnesen L, Kjær I: Cervical column morphology in patients with skeletal open bite. Orthod Craniofac Res 11:17-23, 2008

28. Sonnesen L, Petri N, Kjær I, et al: Cervical column morphology in adult patients with obstructive sleep apnoea. Eur J Orthod 30:521-526, 2008

29. Tangugsorn V, Skatvedt O, Krogstad O, et al: Obstructive sleep apnoea: A cephalometric study. Part I. Cervicocraniofacial skeletal morphology. Eur J Orthod 17:45-56, 1995

30. Thompson DN, Slaney SF, Hall CM, et al: Congenital cervical spinal fusions: A study in Apert syndrome. Pediatr Neurosurg 25:20-27, 1996

31. Ugar DA, Semb G. The prevalence of anomalies of the upper cervical vertebrae in subjects with cleft lip, cleft palate, or both. Cleft Palate Craniofac J 2001; 38:498-503

32. Visscher CM, de Boer W, Lobbezoo F, et al: Is there a relationship between head posture and craniomandibular pain? J Oral Rehabil 29:10301036,2002

33. Wong ML, Sandham A, Ang PK, et al: Craniofacial morphology, head posture, and nasal respiratory resistance in obstructive sleep apnoea: An inter-ethnic comparison. Eur J Orthod 27:91-97, 2005 